\title{
INTERESTING VIEWERS ANALYSIS ON ADVERTISING AT TELEVISION (Case Study of Cigarette Ads for Viewers in the Surabaya Area)
}

\author{
Warsono \\ Industrial Department, Faculty of Technology, Universitas Kartini Surabaya \\ email: warsonounkar@gmail.com
}

\begin{abstract}
The increasing number of advertisers on television, advertising is measured objectively. However, there are still many advertisements that fail, because advertising agencies do not design advertisements in the form of news. To place an ad, the company hires the services of an advertising agency to design and manage the placement of its advertisements. To restore client confidence, an advertising agency must be able to increase creativity and sell advertising effectiveness to clients. So, what they have to do is create a truly effective advertisement in accordance with what they want, which aims to improve the image, status and power of the advertisement they have designed. This study uses a factor analysis method, from 25 question variables reduced to 17 question variables. There are 8 variables that are wasted or considered not important. The 17 variables are included in the new factors that are formed, the number of new factors is 6 factors, namely: advertising components, attractiveness of advertising, advertising goals, style in the implementation of advertising messages, the psychological impact of advertising, and display advertising. The six factors consisting of 17 variables or components of advertising. After calculating using the frequency analysis contained in descriptive statistics, it can be seen that the ad component or ad variable that is most in demand by $T V$ viewers is the humorous ad component with a percentage value of $50.7 \%$
\end{abstract}

Keywords: advertising, promotion, display, psychological, variable

\section{INTRODUCTION}

Marketing strategy is an important issue in a company. In relation to the current domestic economic conditions, companies must be able to develop and implement marketing strategies that can increase the sales volume of their products. Requirements that must be met by a company to be successful in competition are trying to achieve the goal of creating and retaining customers (Fornell, et al, 2012). In order to achieve these goals, each company must strive to produce and deliver goods or services that consumers want by promoting or advertising these goods and services. Each company seeks to develop and implement a marketing strategy by using advertising media to increase product sales volume because marketing is the spearhead for a company. In the increasingly fierce world of competition, companies are demanded to stay alive and thrive. Through advertising media, product characteristics can be known so that consumers can easily recognize them so that they can influence or stimulate consumers to buy and consume (Arvinlucy, 2012). If the product has been purchased according to and meets the tastes of the consumer then the consumer will further become a customer. But it does not stop just like that, every company must strive to continue to innovate and make changes towards more advanced both in product quality, price, company employee work systems and advertising, if it continues to be maintained then a good image is formed about the product.

Around the world, every year no less than US \$ 400 million is spent on advertising. Of that amount, more than US \$200 million is in the United States (US) alone. Reported number of consumers reaches an average of hundreds of advertisements every day. Every time you watch TV, you will see commercials (commercial TV). Aside from being a promotional tool, sometimes an advertisement can be an interesting spectacle, of course, the advertisement has a special attraction, for example the appeal in terms of humor, artist, or story displayed in the ad. So it is not uncommon for TV viewers to be interested in 
the existence of advertisements in lieu of the ongoing program.

\section{Promotion}

\section{LITERATURE REVIEW}

Promotion is an activity aimed at influencing consumers so that they can become familiar with the products offered by the company to them and then they become happy and then buy the product (Jones \& Suh, 2010). The tools that can be used to promote their products entrepreneurs can choose several ways, namely (Liao, et al, 2009): (1) Advertising is the main tool for entrepreneurs to influence their consumers, advertising can be done through newspaper media, radio, magazines, cinema, television, or in the form of posters posted on the roadside or strategic places; (2) Sales promotion is the company's activity to peddle the products that are marketed in such a way that consumers will be easy to see and even by means of certain placement and arrangements, the product will attract the attention of consumers; (3) Personal selling is a company activity to make direct contact with potential customers, which is expected to be a positive relationship or interaction between the entrepreneur and the prospective customer so that the entrepreneur can know the desires and tastes and lifestyle of the consumer. Included in this personal selling category are: door to door selling, mail order, telephone selling, direct selling; (4) Publicity is a method commonly used by entrepreneurs to form an indirect influence on consumers so that they become aware of and like the products that have been marketed.

\section{Advertising}

The word advertising comes from Greek, which means more or less is "leading people to ideas". The definition of advertising is "All forms of activities to present and promote ideas, goods or services that are not personally paid for by certain sponsors". In general, tangible advertising presents non-personal information about a product, brand, company or store that is run at a certain cost compensation (Darke \& Freedman, 2005). Thus advertising is a communication process that aims to persuade or lead people to take actions that are beneficial to the advertisers.

Classification of advertising is divided into 2 main types, namely (Alphonce, et al, 2012): (1) Institutional Advertising, created to create a good attitude towards an institution or an idea and (2) Product Advertising, used by entrepreneurs to carry out various Duty.

\section{The Purpose of Advertising}

The purpose of advertising itself is to persuade customers to buy or consume certain products or services. The purpose of advertising can also be classified according to its objectives, namely (Osuagwu, 2012): (1) Informative Advertising. Aiming at forming a first demand by informing the market about price changes, explaining how a product works, explaining the services available, correcting wrong impressions, reducing buyer anxiety and building a corporate image; (2) Persuasive advertising, aimed at forming the selective demand of a particular brand, is carried out at a competitive stage by forming brand preferences, encouraging brand change, changing buyer perceptions about product attributes, persuading buyers by buying now, and persuading buyers to accept, try or simulate the use of products (Smith and Taylor, 2012); (3) Reminder Advertising, aimed at reminding established products by reminding buyers that the product might be needed later, reminding buyers where to buy it, making buyers remember the product even if it is not in season, and maintaining peak awareness; (4) Value-added Advertising, aims to add brand value to consumer perceptions by innovating, improving quality and strengthening consumer perceptions (Zeithaml, 2003); (5) Other Activist Assistance Ads, aiming to help facilitate the company's other activities in the marketing communication process.

\section{Evaluationand Massage Decision}

Evaluation and selection of messages need to be done after getting the messages created or formed creatively. Good advertising focuses on a core sales proposal. The message based on the desired level is that the message must say something that is desired or interesting to the product (Blattberg, et al, 2018). The message based on exclusivity is that the message must say something exclusive or 
distinguishing that is not found in all brands in the product category. Messages at the level of trust are messages that can be trusted and proven. To determine which attraction has the highest probability of success on a target, market analysis and research must be carried out. The appeal of messages can be created using (Necşulescu, 2011):

1. Celebrity Attraction. Products or brands can stand out in advertising one of them by using the appeal of public figures, can be a person: a TV star, actor, actress, athlete, scientist, and so on (Lavidge, \& Steiner, 1999).

2. Humor. Advertising also uses humor to achieve varied communication goals to spark attention, guide consumers thoroughly to product demands, influence attitudes, perfect the ability to repeat calls from advertisers' demands and ultimately create consumer actions to buy products (Insaf, et al, 2009).

3. Fear appeal. Advertisers motivate consumers to process information and take action, asking for the attraction of fear by identifying two things. First, identify the negative consequences of not using the product or. Second, using unsafe behavior (for example drinking, smoking, calling when driving). The attraction of fear is also effective if the recipient of the message is confident and prefers to control the danger rather than avoiding it and the recipient of the message is not the user of the product (Schultz, et al, 2014).

4. The Attraction Error. The attraction of mistakes can work well because it motivates adult individuals to emotionally take over responsibility for leading-edge actions to reduce the level of mistakes. Advertisers use the appeal of mistakes and try to persuade potential consumers by implementing feelings of guilt can be replaced by using the advertised product (Kim, et al, 2011).

5. Music Attraction. Music is an important component in advertising. Jinggel, background music, famous tunes, and classical arrangements are used to attract attention, convey point of sale, set an emotional tone for an advertisement and influence the feelings of the listener. Many practitioners and advertising academics think of the form of musical variety used for the communication function (Hartley \& Cross, 2008).

6. Comparative Attraction. The practice in advertising, the direct or indirect comparative of a product with a competing product, which promotes that the product is superior to competing products in the consideration of purchasing is called comparative advertising (Chandon, et al, 2010).

\section{RESEARCH METHODOLOGY}

This research has any step, such:

a. Stage of Introduction

(1) Identification and Problem Statement

It is an initial stage for researchers in making an introduction and understanding as well as formulating all forms of problems that exist in the case being faced. This stage is also the stage of gathering information to determine, identify and formulate problems. By compiling a questionnaire that is easily understood by respondents so that it can absorb the desired information optimally. The problem solved through this research is "Analysis of Audience's Interest in Advertisements on Television"

(2) Research Objectives

The purpose of this study is to find out what factors and components of advertising make an ad interesting for TV viewers and how the respondent segmentation forms. With the determination of the objectives of this study it can provide clear direction for the implementation of further research and research becomes more focused on the problems.

(3) Field Study

The next step is a preliminary study, this step is important to know or know more about the conditions or conditions in the field that we will examine. 
(4) Literature Review

Aiming to deepen and understand the theories and methods that will be used in solving existing problems. This study was conducted to look for theories in the form of books, final assignments, magazines, newspapers, television and internet surveys that can be used as references and references in solving problems.

b. Stage of Data Collection

(1) Identification of Research Variable Identify what variables will be used for data collection and processing in the analysis of audience interest in adverts on television. By observing the condition of the object of research can be known influential variables which can later be used in making the questionnaire.

(2) Identification of Research Sampling The sample is part of the number and characteristics possessed by the population. If the population is too large and researchers may not learn everything that exists in the population for example due to limited funds, manpower and time, then researchers can use samples taken from that population.

(3) The making of this initial questionnaire

The making of this initial questionnaire was conducted with the aim of identifying with certainty what factors contained in an advertisement so that it could attract the attention of television viewers, besides it was also expected to produce the factors considered the most important in an advertisement so as to make the advertisement favored by television viewers.

(4) Questionnaire distribution (Pre Sampling)

Questionnaire distribution is a temporary or initial sampling technique before actual sampling, which is used to find out whether the questionnaire that exists and has been arranged is really easy to understand and relates to the research conducted. For this reason, if there are errors or deficiencies, improvements can be made. The preliminary questionnaire was only distributed as many as 30 pieces to respondents who were considered to represent in accordance with existing provisions.

(5) Validity and Reliability Test

Validity is a statement of the extent to which the data contained in a questionnaire can measure what you want to be measured. Validity test is a test / measurement of how precisely a data collection instrument performs its size function.

Reliability is an index that shows the extent to which the gauges are reliable or reliable. Reliability here can mean how many times the variables in the questionnaire are asked to respondents who are different then the results will not deviate far from the average respondent's answer to the veriabel. Each measuring device should have the ability to provide consistent measurement results. By using the Cronbach Alpha () method, it is declared reliable because $r$ count $>r$ table. While the value of $r$ ranges from 0 to 1 , the smaller the measurement error, the more reliable the measuring device (approaching the actual condition).

c. Data Processing

This stage is the data processing stage that has been obtained from the distribution of questionnaires in the research that has been determined. In this study data were processed using factor analysis and cluster analysis.

d. Analysis and Interpretation

In this stage, researchers look for and analyze data processing that is able to describe the real conditions of the problem being studied.

e. Conclusion and Suggest

From the results of the analysis and interpretation, several conclusions will 
be drawn which will be the final results of this study and the inclusion of suggestions addressed to all those who have read this research.

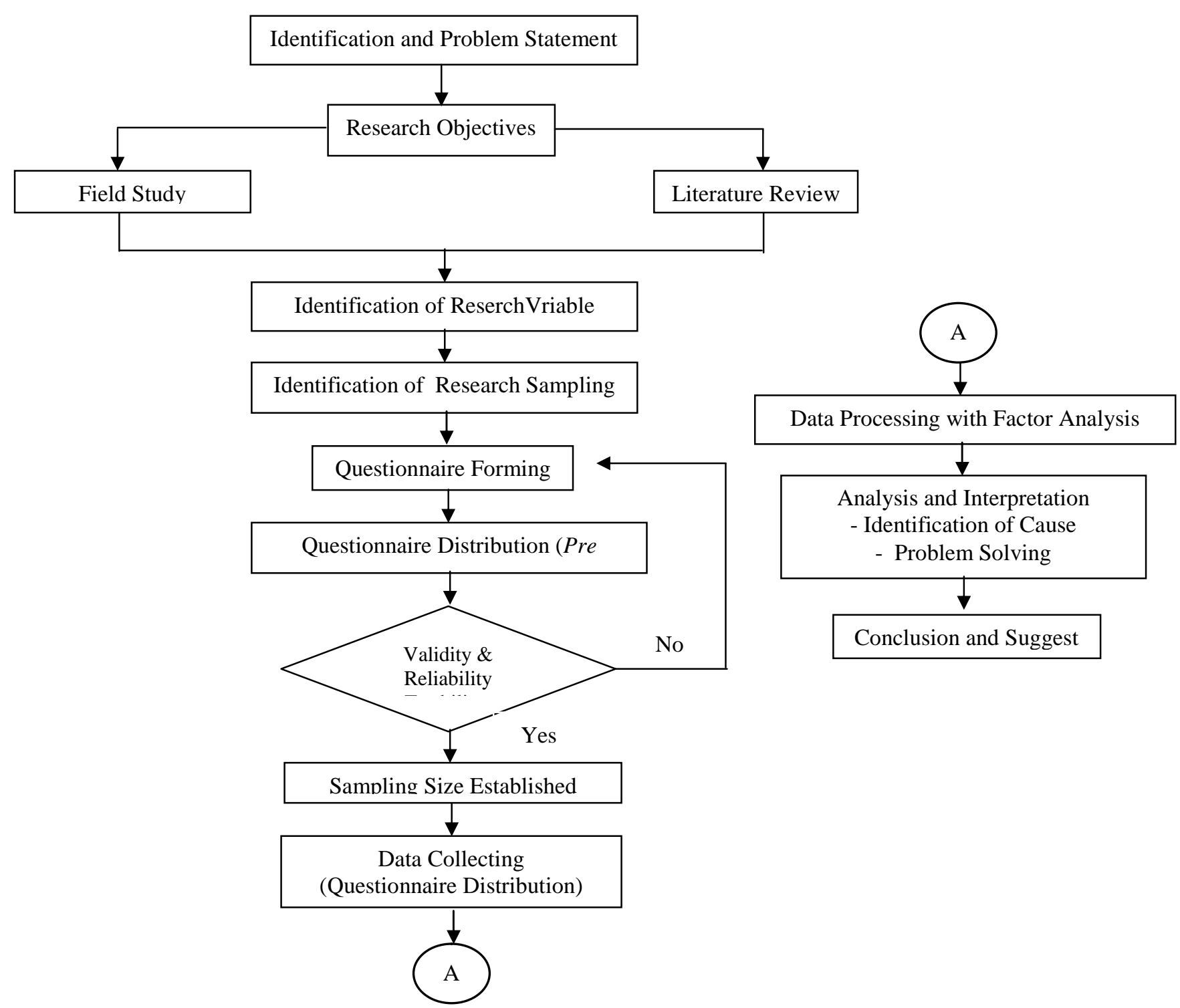

Figure 1. Research Methodology

\section{RESULT AND DISCUSION}

\subsection{Sampling Collecting}

Sampling in this study is to use a simple random sampling method, which is a form of sampling with reference to the assumption that members of the population have the same opportunity to be selected as respondents. The questions that have been made are distributed by distributing initial test questionnaires or often called pre sampling to 30 respondents, and the results are 27 questionnaires are 16 | TiBuana, Vol. 03, No. 2, 2020 eligible and 3 questionnaires are not eligible alias defects.

$\mathrm{Z}_{(1-\alpha / 2)}=$ Convidence interval at $95 \%$

Where $: n \geq \frac{(1,96)^{2}(27 / 30)(3 / 30)}{(0,05)^{2}}$

$\mathrm{n} \geq \frac{(3,8416)(0,9)(0,1)}{0,0025}$ 


$$
\mathrm{n} \geq 138,2976
$$

From the calculations carried out it is determined that the minimum number of samples to be investigated is 138.2976 or 139 samples distributed in the city of Surabaya, but to get closer to the truth more 150 samples will be distributed. Surabaya is divided into 5 parts or sub-districts, therefore the questionnaire is distributed in 5 sub-districts with the number of questionnaires in each region as follows:

Table 1

Number of Male Population in Surabaya

\begin{tabular}{lrr}
\hline \multicolumn{1}{c}{ Number } & Number of Male & Number of Sampling \\
\hline Central Surabaya & 193.052 & $15 \%$ X $150=22,5 \approx 22$ sampling \\
North Surabaya & 247.595 & $19,24 \%$ X $150=28,86 \approx 29$ sampling \\
East Surabaya & 319.292 & $24,8 \%$ X $150=37,2 \approx 37$ sampling \\
South Surabaya & 324.644 & $25,2 \%$ X $150=37,8 \approx 38$ sampling \\
West Surabaya & 202.405 & $15,73 \%$ X $150=23,6 \approx 24$ sampling \\
Total & 1.286 .988 & \\
\hline
\end{tabular}

\subsection{Validity and Reliability Test}

To conclude the results of the validity and reliability test, the coefficient (validity and reliability) is consulted with the critical value (rtable), the significance level is 5\%. A statement is considered valid if the total correlation coefficient is greater than the critical value (rtable), conversely if the total correlation coefficient is smaller than the critical value (rtable) then the statement is considered invalid or null. While the reliability test of the measuring instrument is done by looking at the alpha value in alpha analysis, if the alpha value is greater than 0.5 then it is said to be reliable. In the study of 150 questionnaires obtained an alpha value of 0.8241 which means that the value is greater than 0.5 then it is said to be reliable. Based on validity and reliability tests for data as many as 150 questionnaires that have been distributed to respondents in the Surabaya Region

Table2

Test Results of Consumer Perception Value Validity

\begin{tabular}{|c|c|c|c|c|c|}
\hline $\begin{array}{c}\text { Item of } \\
\text { Questiion }\end{array}$ & $\begin{array}{l}\mathrm{r} \text { calculate for perception } \\
\text { value } \mathrm{df}=148 \mathrm{n}=150 \\
\quad(\mathrm{r} \text { table }=0,135)\end{array}$ & Conclusion & $\begin{array}{c}\text { Item of } \\
\text { Questiion }\end{array}$ & $\begin{array}{l}\text { r calculate for perception } \\
\text { value } \mathrm{df}=148 \mathrm{n}=150 \\
\quad(\mathrm{r} \text { table }=0,135)\end{array}$ & Conclusion \\
\hline 1 & 0,5217 & Valid & 14 & 0,1585 & Valid \\
\hline 2 & 0,3734 & Valid & 15 & 0,1491 & Valid \\
\hline 3 & 0,4003 & Valid & 16 & 0,1740 & Valid \\
\hline 4 & 0,3220 & Valid & 17 & 0,6543 & Valid \\
\hline 5 & 0,2091 & Valid & 18 & 0,3827 & Valid \\
\hline 6 & 0,1722 & Valid & 19 & 0,4401 & Valid \\
\hline 7 & 0,4807 & Valid & 20 & 0,6196 & Valid \\
\hline 8 & 0,4208 & Valid & 21 & 0,5234 & Valid \\
\hline 9 & 0,3030 & Valid & 22 & 0,2350 & Valid \\
\hline 10 & 0,3722 & Valid & 23 & 0,5479 & Valid \\
\hline 11 & 0,2259 & Valid & 24 & 0,6930 & Valid \\
\hline 12 & 0,3442 & Valid & 25 & 0,4497 & Valid \\
\hline 13 & 0,1454 & Valid & & & \\
\hline
\end{tabular}




\subsection{Data Processing with Factor Analysis Method}

At this stage, the data that has been collected is processed using factor analysis. The number of questions in the questionnaire is 25 questions that contain the components of advertising, this factor analysis principle is to reduce data or summarize a number of variables to be smaller and give the name of the new variables formed. So out of the 25 advertising component questions, after a factor analysis is formed it is formed into 6 factors consisting of 17 ad components. So there are 8 components of advertising that are wasted or considered not important, for the calculation can be seen in Appendix 4, namely the factor analysis test (Rotated Component Matrix). Below we can see the new factors that formed:

1. Data Processing with Descriptive Statistics Method

For the next data processing we use descriptive statistical methods on the Frequencies menu, this menu can be used to display and describe (describe) data consisting of only one variable. As in the data processing that we are making at this time, we are looking for the number of frequencies of respondents' answers along with valid percent who chose answers strongly disagree (1), disagree (2), doubt (3), agree (4), strongly agree (5) for each ad component available. After getting the number of answers to each ad component, then we can find out the percentage of each answer from each ad component and also the number of respondents who chose the ad component that is formed from the existing factors.

2. Grouping Respondents

At this stage begins with the grouping of respondents into groups that distinguish one group from another group. In other words, at this stage respondents begin to be entered into segments with the homogeneity of the respondent given by the respondent to the stimulation (attributes) given through the questionnaire given spread out.

3. Data Processing with Cluster Analysis Method
After the respondents are grouped, they are processed using the cluster analysis method. Cluster analysis is divided into two types namely: (a) Hierarchy cluster. Hierarchical clustering is usually used for relatively small amounts of sample (data); (b) K-means Cluster. Used for a large number of samples (data) (over 200 samples). Because the number of samples (data) that we process as many as 150 samples, we use a hierarchical cluster.

\subsection{Analysis and Interpretation}

\section{Analysis of New Factor Formation}

In the first table, KMO and Bartlett's test, we can see that the K-M-O Measure of Sampling Adequacy (MSA) is 0.673 . Because the MSA number is above 0.5 , the set of variables can be further processed. Next, each variable is analyzed to find out which can be further processed and which should be excluded. The same conclusion can also be seen in the Barlett's Test number (shown by the ChiSquare number) of 1236,067 with a significance of 0,000 . In the second table (Anti Image Matrices), especially at the bottom (Anti Image Correlation), a number of diagonal figures, marked 'a', are shown, indicating the amount of MSA of a variable. Like layout variables that have MSA 0.609, then complete variables with MSA of 0.635 and so on. In the third table (Total Variance Explained), there are 17 variables included in the factor analysis. With each variable having a variance of 1 , the total variance is $17 \times 1=$ 17. Now, if the seventeen variables are 'summarized' into one factor, the variance that can be explained by one factor is: $4,245 / 17 \times 100 \%=24.97 \%$.

If 17 variables are extracted into 6 factors, then: The first factor variance is $24.97 \%$, the second factor variance is $2.788 / 17 \mathrm{x} 100 \%$ $=16.4 \%$, the third factor variance is $1.887 \mathrm{I}$ $17 \times 100 \%=11.016 \%$, the variance the fourth factor is $1.429 / 17 \times 100 \%=8.406$, the fifth factor variance is $1.238 / 17 \times 100 \%$ $=7.284 \%$, the sixth factor variance is $1.052 \mathrm{I}$ $17 \times 100 \%=6.189 \%$. The total of the six factors will explain $24.97 \%+16.4 \%+$ $11.016 \%+8.406 \%+7.284 \%+6.189 \%=$ 
$74.265 \%$ of the variability of the seventeen original variables. Whereas eigenvalues indicate the relative importance of each factor in calculating the variance of the seventeen variables analyzed. Note here that:

a. The number of eigenvalues for the seventeenvariables is the same as the total variance of the seventeenth variable, or $4,245+2,788+1,873+1,429+1,238+$ $1,052+0,777+0,698+0,592+0,501+$ $0,412+0,389+0,348+0,292+0,157+$ $0,131+0,137+1,052+0,777+0,698+$ $0,592+0,501+0,412+0,389+0,348+$ $0,292+0,157+0,131+0,137+1,052+$ $0,777+0,698+0,592+0,501+0,412+$ $0,389+0,348+0,292+0,157+0,131+$ $0,131+, 1,052+0,777+0,698+0.592+$ $0.501+0,412+0,389+0,348+0,292+$ $0,157+0,131+0,131+$, respectively, and a total number of variables. $0.077=17$

b. The composition of eigenvalues is always sorted from the largest to the smallest, with the criterion that the number of eigenvalues below 1 is not used in calculating the number of factors formed.

After knowing that the six factors are the optimal number, this table shows the distribution of the seventeen variables in the six factors. While the figures in the table are loading factors, or the magnitude of the correlation between a variable with a factor of 1 , factor 2 , factor 3 , factor 4 , factor 5 , or factor 6. Next is the Scree Plot, which explains the basis of the number of factors obtained by display of a graphic. It appears that from one to six factors (the line from the component number axis $=1$ to 6 ), the direction of the line decreases quite sharply. Then from number 6 to number 7 , the line is still decreasing, but with a smaller slope. Also notice that component number 7 is below the number 1 of the $\mathrm{Y}$ axis (eigenvalues), until the component number to the 17 line direction decreases. This shows that the six factors are best for 'summarizing' the seventeen variables.

\section{Respondent Frequency Analysis}

In factor 1 consists of: variable 10, variable 17 , variable 21 , and variable 22 .

a. In variable 10 , the number of respondentswho chose answer 1 was 11 people, who chose answer 2 as many as
17 people, who chose answer 3 as many as 25 people, who chose answer 4 as many as 62 people, who chose answer 5 as many as 35 person.

b. In variable 17, the number of respondents who chose answer 1 was 2 people, who chose answer 2 as many as 40 people, who chose answer 3 as many as 28 people, who chose answer 4 as many as 71 people, who chose answer 5 as many as 9 person.

c. In variable 21, the number of respondents who chose answer 1 was 16 people, who chose answer 2 as many as 15 people, who chose answer 3 as many as 19 people, who chose answer 4 as many as 34 people, who chose answers to 5 as many as 66 people

d. In variable 22 the number of respondents who chose answer 1 was 1 person, who chose answer 2 as many as 16 people, who chose answer 3 as many as 17 people, who chose answer 4 as many as 70 people, who chose answer 5 as many as 46 people.

In factor 2, it consists of: variable 3, variable 7, variable 8 , variable 24

a. In variable 3 , the number of respondents whochose answer 1 was 0 meaning no one chose, who chose answer 2 as many as 17 people, who chose answer 3 as many as 39 people, who chose answer 4 as many as 72 people, who chose answer 5 as many as 22 people.

b. In variable 7 , the number of respondents who chose answer 1 was 20 people, who chose answer 2 as many as 0 , who chose answer 3 as many as 15 people, who chose answer 4 as many as 76 people, who chose answer 5 as many as 39 people.

c. In variable 8 , the number of respondents who chose answer 1 was 7 people, who chose answer 2 as many as 49 people, who chose answer 3 as many as 27 people, who chose answer 4 as many as 3 people, who chose answer 5 as many as 64 people.

d. In variable 24 , the number of respondents who chose answer 1 was 0 , who chose answer 2 as many as 22 people, who chose answer 3 as many as 24 people, who chose 
answer 4 as many as 46 people, who chose answer 5 as many as 58 people.

In factor 3 consists of: variable 1, variable 5 , variable 12 , variable 16 .

a. In variable 1 , the number of respondentswho chose answer 1 was 15 people, who chose answer 2 as many as 63 people, who chose answer 3 as many as 35 people, who chose answer 4 as many as 25 people, who chose answer 5 as many as 12 people.

b. In variable 5, the number of respondents who chose answer 1 was 19 people, who chose answer 2 as many as 41 people, who chose answer 3 as many as 20 people, who chose answer 4 as many as 47 people, who chose answer 5 as many as 23 people.

c. In variable 12, the number of respondents who chose 1 st answer was 4 people, who chose 2nd answer as many as 37 people, who chose $3 \mathrm{rd}$ answer as many as 38 people, who chose 4th answer as many as 50 people, who chose 5 th answer as many as 21 people.

d. In variable 16, the number of respondents who chose the 1 st answer was 10 people, who chose the 2nd answer as many as 57 people, who chose the 3rd answer as many as 29 people, who chose the 4th answer as many as 29 people, who chose the 5th answer as many as 25 people.

In factor 4 consists of: variable 4 and variable 15.

a. In variable 4 , the number of respondents whochose answer 1 was 7 people, who chose answer 2 as many as 9 people, who chose answer 3 as many as 29 people, who chose answer 4 as many as 55 people, who chose answer 5 as many as 50 people.

b. In variable 15, the number of respondents who chose answer 1 was 8 people, who chose answer 2 as many as 26 people, who chose answer 3 as many as 44 people, who chose answer 4 as many as 42 people, who chose answer 5 as many as 30 people.

$20 \mid$ TiBuana, Vol. 03, No. 2, 2020
In factor 5 consists of: variable 2 and variable 13.

a. In variable 2, the number of respondents whochose answer 1 was 10 people, who chose answer 2 as many as 23 people, who chose answer 3 as many as 17 people, who chose answer 4 as many as 64 people, who chose answer 5 as many as 36 people.

b. In variable 13 , the number of respondents who chose answer 1 was 2 people, who chose answer 2 as many as 27 people, who chose answer 3 as many as 25 people, who chose answer 4 as many as 62 people, who chose answer 5 as many as 34 people.

In factor 6 consists of: variable 11. In variable 11 , the number of respondents who chose answer 1 was 7 people, who chose answer 2 as many as 31 people, who chose answer 3 as many as 30 people, who chose answer 4 as many as 49 people, who chose answer 5 as many as 33 people.

\section{Age Cluster Analysis}

The first table (Initial Cluster) is the first two clusters to form. Then the K-Means Cluster method will test and reallocate the existing clusters. The process is called iteration, which contains changes to the initial cluster (Change In Cluster Center). The result of K-means is the final cluster center, which contains two clusters to divide 150 respondents based on their respective ages.

In the final cluster center table, the price for cluster 1 (1.54) shows that this means that cluster 1 consists of age group 1 and age group 2 (because 2 is closer to the value of 1.54 than the value of 3.12). The age group 1 is the age group under 20 years ( $<20$ years) while the age group 2 is the age group between 20 years and less than 30 years $(20<30$ years $)$. The final cluster center table shows the price for cluster 2 (3.12). This means that cluster 2 consists of age group 3 and age group 4 (because 4 is closer to the value of 3.12 than the value of 1.54). The age group 3 is the age group between 30 years and less than 40 years (30$<40$ years) while the age group 4 is the age group greater or equal to 40 years (40 years). 
In the last number of cases in each cluster, it is explained that the number of respondents for cluster 1 is 124 people, while the number of respondents for cluster 2 is 26 people, so the total number of respondents is 150 people.

4. Job Cluster Analysis Clusters of work are thesame as age clusters. In the final cluster center table, the price for cluster 1 (1.51) shows that cluster 1 consists of work group 1 and work group 2 (because 2 is closer to the value of 1.51 than value of 3.85). The work group 1 is the student work group / student while the work group 2 is the civil service work group. The final cluster center table shows the price for cluster 2 (3.85). This means that cluster 2 consists of work group 3 and work group 4 (because 4 is closer to the value of 3.85 than with a value of 1.51), and expert group 5 (because the value of 5 is closer to the value of 3.85 than with the value of 1.51). The work group 3 is a work group as a private employee, work group 4 is an entrepreneurial work group, and work group 5 is another work group. In the last number of cases in each cluster, it was explained that the number of respondents for cluster 1 was 116 people, while the number of respondents for cluster 2 was 34 people, so the total number of respondents was 150 people.

5. Education Cluster Analysis Education clustersare the same as age clusters and occupational clusters, in the final cluster center table, the price for cluster 1 (2.43) shows that cluster 1 consists of education group 1 (because 1 is closer to the value of 2.43 than with a value of 4.59) and education group 2 (because 2 is closer to the value of 2.43 than the value of 4.59), and education group 3 (because 3 is closer to a value of 2.43 than with a value of 4.59 ). The education group 1 is the elementary education group, and the education group 2 is the junior high education group, while the education group 3 is the high school education group. As for the final cluster center table, the price for cluster 2 (4.59) shows that this can be interpreted that cluster 2 consists of education group 4 (because the value of 4 is closer to the value of 4.59 than the value of 2.43) and the education group 5 (because 5 is closer to the value of 4.59 than the value of 2.43). The education group 4 is the education group as Diploma (D1, D2, D3) while the education group 5 is the education group Bachelor (S1, S2, S3).

\section{CONCLUSION}

1. From the results of data processing using thefactor analysis method, from 25 question variables reduced to 17 question variables. So there are 8 variables that are wasted or considered not important. And the 17 variables are included in the new factors that are formed which the number of new factors are 6 factors, among others: ad component factors, ad attractiveness factors, advertisement destination factors, style factors in the implementation of advertising messages, advertisement psychological impact factors, factors display ad.

2. After knowing the respondent segmentation forms which are divided into two clusters, then the largest number of clusters must be paid more attention in terms of advertising, for example in the age cluster group, the one or age group $(<20$ years) must be considered and age group (20- $<30$ years) because the number of clusters one is greater than the number of clusters two, and applies forever to clusters of work, education, status, and expenditure. 


\section{REFERENCE}

1. Alphonce, J.O., Victor, L.A., Fredrick, O.A., Patrick, B.A., Beatrice, E.A., \& Odhiambo, O. (2012). Influence of promotional strategies on banks performance. International Journal of Business, Humanities and Technology, 2(5), 169-178.

2. Arvinlucy, A.O. (2012). An evaluation of promotional elements influencing sales of an organization: A case study of sales of agricultural and non - agricultural products among women groups in Homa Bay District, Kenya. International Journal of Business and Social Science, 3(5).

3. Blattberg, R. C., Eppen, G. D., \& Lieberman, J. (2018). A theoretical and empirical evaluation of price deals in consumer non-durables. Journal of Marketing, (winter), 11-15.

4. Changju Kim, Yingzi $\mathrm{Xu}$, Kenneth F. Hyde. (2011). Advertising versus Sales Promotion: An Examination of the Japanese Food Industry, 1976-2008. Journal of Global Scholars of Marketing Science 21, 193-200.

5. Chandon, P., Wansink, B., \& Laurent, G. (2010). A benefit congruency framework of sales promotion effectiveness. Journal of Marketing, 64 (4), 65-81.

6. Darke, P.R. \& Freedman, J.L. (2005). Nonfinancial motives and bargain hunting. Journal of Applied Social Psychology, 25, 1597-1610.

7. Fornell, C., Robinson, W.T., Wernerfelt, B. (2012). Consumption Experience and Sales Promotion Expenditure. Management Science, Vol 31, (9).

8. Hartley, S.W. \& Cross, J. (2008). How sales promotion can work for and against you. Journal of Consumer Marketing, 5, $35-42$.
9. Insaf Ben Amor, Francis Guilbert. (2009). Influences on free samples usage within the luxury cosmetic market. Direct Marketing: An International Journal 3:1, 67-82

10. Jones, M. A. \& Suh, J. (2010). Transaction-specific satisfaction and overall satisfaction: an empirical analysis. Journal of Services Marketing, 14 (2), 147-59.

11. Lavidge, R. J. \& Steiner, G.A. (1999). A model for predictive measurement of advertising effectiveness. Journal of Marketing, 25(1), 59-60.

12. Liao, S., Shen, Y., \& Chu, C. (2009). The effects of sales promotion strategy, product appeal and consumer traits on reminder impulse buying behaviour. International Journal of Consumer Studies, 33 (3), 274-284.

13. Necşulescu E. (2011). Evolutions and Trends in Presenting the Profit and Loss Account as Part of the Annual Financial Statements. EIRP Proceedings, the $6^{\text {th }}$ Edition.

14. Osuagwu, L. (2012). Marketing Principle and Management. ${ }^{\text {nd }}$ Edition. Lagos: Grey Reserve limited.

15. Schultz, D. E., Block, M. P. (2014). Sales promotion influencing consumer brand preferences/purchases. Journal of Consumer Marketing, 31 (3), 212 - 217

16. Smith, P. R. and Taylor, J. (2012). Marketing Communications: An Integrated Approach. $3^{\text {rd }}$ Edition. Great Britain: Bill and Bain Ltd.

17. Zeithaml, V.A. (2003). Consumer perceptions of price, quality and value: a means-end model and synthesis of evidence. Journal of Marketing, 52 , $2-$ 22 